\title{
Own attractiveness and perceived relationship quality shape sensitivity in women's memory for other men on the attractiveness dimension
}

Christopher D. Watkins

Mike J. Nicholls

Carlota Batres

Dengke Xiao

Sean Talamas

David I. Perrett

This is the accepted manuscript (C) 2017, Elsevier Licensed under the Creative Commons Attribution-NonCommercialNoDerivatives 4.0 International: http://creativecommons.org/licenses/bync-nd/4.0/

\section{$((\mathrm{coc})$ EY-NO-ND}

The published article is available from doi:10.1016/j.cognition.2017.03.007 
1 Own attractiveness and perceived relationship quality shape sensitivity in

2 women's memory for other men on the attractiveness dimension

3

4 CHRISTOPHER D WATKINS ${ }^{1 *}$, MIKE J NICHOLLS ${ }^{1}$, CARLOTA BATRES ${ }^{2}$, DENGKE

$5 \quad \mathrm{XIAO}^{2}$, SEAN TALAMAS ${ }^{2}$ AND DAVID I PERRETT²

6

$7{ }^{1}$ Division of Psychology, School of Social and Health Sciences, Abertay University,

8 Dundee Scotland DD1 1HG.

9

10 2School of Psychology and Neuroscience, University of St Andrews, St Mary's Quad,

11 South Street, St Andrews, Fife, KY16 9JP.

12

*Corresponding author

14 Christopher Watkins

15 Division of Psychology, Abertay University, Dundee Scotland DD1 1HG.

16 Phone: +44(0)1382 308646

17 Fax: $+44(0) 1382308749$

18 Email: c.watkins@abertay.ac.uk

19

20 Word count: 7592 words 
Own attractiveness and perceived relationship quality shape sensitivity in women's memory for other men on the attractiveness dimension
Abstract
Although recent work suggests that opposite-sex facial attractiveness is less salient in memory when individuals are in a committed romantic relationship, romantic relationship quality can vary over time. In light of this, we tested whether activating concerns about romantic relationship quality strengthens memory for attractive faces. Partnered women were exposed briefly to faces manipulated in shape cues to attractiveness before either being asked to think about a moment of emotional closeness or distance in their current relationship. We measured sensitivity in memory for faces as the extent to which they recognized correct versions of studied faces over versions of the same person altered to look either more or less-attractive than their original (i.e. studied) version. Contrary to predictions, high relationship quality strengthened hit rate for faces regardless of the sex or attractiveness of the face. In general, women's memories were more sensitive to attractiveness in women, but were biased toward attractiveness in male faces, both when responding to unfamiliar faces and versions of familiar faces that were more attractive than the original male identity from the learning phase. However, findings varied according to self-rated attractiveness and a psychometric measure of the quality of their current relationship. Attractive women were more sensitive to attractiveness in men, while their less-attractive peers had a stronger bias to remember women as more- attractive and men as less-attractive than their original image respectively. Women in better-quality romantic relationships had stronger positive biases toward, and false memories for, attractive men. Our findings suggest a sophisticated pattern of sensitivity and bias in women's memory for facial cues to quality that varies systematically according to factors that may alter the costs of female mating competition ('market demand') and relationship maintenance.

Keywords: Person memory, quality, female competition, extra-pair mating, identity 


\section{Introduction}

Attractiveness is a critical dimension of face perception (see, e.g., Little et al., 2011; Rhodes, 2006; Todorov et al., 2015 for reviews). For example, we categorize potential social and/or romantic partners on both the attractiveness (Willis \& Todorov, 2006) and valence trait-dimensions (Oosterhof \& Todorov, 2008) with minimal exposure to their face and associate attractiveness with a variety of positive trait-attributions (Dion et al., 1972; reviewed in Langlois et al., 2000). Positive evaluations of attractive individuals may have evolved to maximize reproductive fitness by associating with individuals of good physical condition who, in turn, are better-placed to confer benefits onto recipients (see, e.g., Gangestad \& Scheyd, 2005; Krupp et al., 2011; Sell et al., 2009 for discussion). Consistent with this proposal, attractive facial characteristics are positively correlated with putative measures of good underlying health (e.g., Gangestad et al., 2010; Lie et al., 2008; Rantala et al., 2011) and, in men, their reproductive success (Prokop \& Fedor, 2011). Physical attractiveness is also an important dimension of mating competition among women, who enhance their attractiveness and/or denigrate rivals based on their attractiveness (reviewed in Vaillancourt, 2013). Collectively, attractiveness is a salient cue in potential mates and rivals for mates.

Putative cues to quality shape learning and memory for mates across many nonhuman species (see, e.g., Bailey \& Zuk, 2009; Brennan \& Kendrick, 2006; Dukas, 2008 for reviews). Episodic memory and the ability to mentally simulate past and future transactions (Suddendorf et al., 2009) is thought to be functionally-specialized to fulfil our current goals (Conway, 2005), including goals that maximize reproductive fitness (see Kenrick et al., 2010 for discussion). Accordingly, cues to quality in humans, such as facial attractiveness, shape cognitive processes such as attention and memory (see 
also Wiese et al., 2014 for a recent discussion). For example, location memory (Becker et al., 2005) is enhanced when viewing physically-attractive women and individuals take longer to disengage their attention from attractive women's faces toward an alternate target than they do for average-looking faces or attractive men's faces (Maner et al., 2007a). Moreover, experimentally-activating mating goals increase attentional-fixation toward attractive potential mates (Maner et al., 2007b). Biases in memory for attractive faces are underpinned by neural mechanisms involved in encoding and the processing of reward (Tsukiura \& Cabeza, 2011), complementing work that demonstrates increased effort allocated to view attractive faces in experimental paradigms (e.g. 'pay-per-view'; reviewed in Hahn \& Perrett, 2014). Collectively, attractiveness modulates face-processing through various neural stages of memory, independent of cues such as facial expression (Marzi \& Viggiano, 2010).

Consistent with a 'goal-driven' account of memory and cognition (Conway, 2005; Kenrick et al., 2010), the effects of facial attractiveness on person memory are also shaped by personal and contextual factors. For example, attention-to and memory-for attractive same-sex rivals is enhanced among jealous individuals (Maner et al., 2009a; see also Maner et al., 2007a) and attention toward attractive mates is weaker among those who have a weaker preference for short-term, uncommitted relationships (Maner et al., 2007a). Of interest to the current study, the motive to attract a romantic partner appears to bias memory for attractive faces. For example, attentional fixation toward attractive potential mates is reduced in partnered compared to single individuals (Maner et al., 2009b). Moreover, reverse-correlation paradigms demonstrate that partnered women have a less-attractive internal representation of other men's faces than un-partnered women do (Karremans et al., 2011). Collectively, these findings suggest that psychological and circumstantial factors, such as one's 
relationship status, bias memory for facial cues to attractiveness in ways that may function to maintain long-term romantic relationships.

In the current experiment, we extend this line of reasoning (Karremans et al., 2011) to test for effects of short-term changes in the quality of women's romantic relationship and their memory for attractive faces. Romantic relationship quality varies over time (Karney \& Bradbury, 2005; see also Berscheid, 2010) and, on average, declines over time (Finkel et al., 2013). Relationship maintenance is an important functional goal (see Maner et al., 2008 for discussion) and monogamy may have been critical to the long-term reproductive fitness of certain species of primate (those at risk of infanticide; Opie et al., 2013). Researchers have proposed that forms of romantic expression, such as communicating love and kissing (Wlodarski \& Dunbar, 2013), function, at least partly, for individuals to communicate a future commitment to their relationship (Ackerman et al., 2011). Accordingly, studies of divorcees cite lack of closeness, attention and communication as primary reasons for relationship dissolution (De Graaf \& Kalmijn, 2006). Large-scale cross-cultural data suggests, however, that extra-pair partnerships are the primary cause of relationship dissolution (Betzig, 1989). Indeed, ancestral women are also thought to have engaged in extrapair mating to increase reproductive fitness (Shackelford \& Goetz, 2007; see also Jennions \& Petrie, 2000). Here, we propose two alternate, although not necessarily mutually-exclusive, predictions. If relationship maintenance is important to maximize fitness (see Maner et al., 2008) and attractive females are effective competitors for mates (e.g., Puts et al., 2011; Vaillancourt, 2013), activating concerns about relationship quality via experimental priming would be predicted to increase female sensitivity in memory for attractive women. Secondly, if low relationship quality increases the salience of attractive extra-pair partners (e.g., to increase female fitness 
126 Shackelford \& Goetz, 2007; see also Jennions \& Petrie, 2000), activating concerns

127 about relationship quality via experimental priming would be predicted to increase female sensitivity in memory for attractive men.

We also test for two other potentially-moderating factors in the current experiment. As mental simulation is a fundamental component of episodic memory (Suddendorf et al., 2009), it is important to control for the typical quality of one's romantic relationship when testing for effects of short-term/flexible changes to perceived relationship quality on women's memory for other people. Indeed, as the average decline in relationship quality over time is thought to be due, in part, to greater accessibility in memory of potential stressors and responses to disputes that accumulate in a close relationship through time (e.g., 'negative affect reciprocity'; see Finkel et al., 2013), memory for attractive faces would also be predicted to correlate negatively with relationship quality when measured psychometrically. Secondly, as extra-pair partnerships (Vaillancourt, 2013) and relationship dissolution (Perilloux \& Buss, 2008) are costly acts, partnered women's memory for other men may be specialized in light of their ability to compete for alternate mates, such as factors that predict their demand on the 'mating market' (e.g., their own attractiveness). Consistent with biological markets theory, where individuals of higher 'market value' are betterplaced to translate their preferences into choices (Noë \& Hammerstein, 1994), recent research suggests that partnered women's own attractiveness predicts the association between their preferences and actual choices for facial cues to male quality (Wincenciak et al., 2015). This relationship would be predicted to extend to women's stored knowledge, and potential choices of extra-pair partners, since putative cues to quality in women are positively correlated with their reported number of extra-pair partners and sexual partners more generally (Hughes et al., 2004; Rhodes et al., 
151 2005). Thus, we also test whether partnered women's memory for attractive men is

152 predicted by their own attractiveness, as attractive women would be expected to incur fewer costs from extra-pair partnerships or mating competition more generally (see also Vaillancourt, 2013 for discussion).

\section{Method}

\subsection{Participants}

Seventy-four heterosexual women (Mean age $=24.94$ years, $S D=6.79$ years) took part in our experiment. Participants were recruited on campus and within the Tayside area and received either $£ 5$ or course credit for taking part. We specifically recruited individuals who were currently in long-term romantic relationships of at least eight months in duration, in order to maximize potential variability in positive/negative memories accessible to participants over the course of their relationship (mean relationship length $=45.49$ months, $S D=46.97$ months). We scheduled data collection to finish mid-November 2015. All procedures were granted full ethical approval from the School of Social and Health Sciences Ethics Committee at Abertay University.

\subsection{Face stimuli}

We used prototype-based image transformation to objectively and systematically manipulate attractiveness in a set of 2D White-Caucasian faces (see Tiddeman et al., 2001). Here, $100 \%$ of the linear differences in $2 \mathrm{D}$ shape between attractive and lessattractive prototypes of a male and female face were added to or subtracted from same-sex digital face images of 32 young White-Caucasian adults (16 male, 16 female, Mean age $=23.09$ years, $S D=2.99$ years). Our attractive and less-attractive prototypes (two male, two female) were constructed based on the attractiveness 
176 ratings of a set of faces by a separate panel of judges (99 female, 74 male, Mean age

$177=28.26$ years, $S D=11$ years). All face images were taken from a publicly-available 178 face set (3d.sk) used in prior research (e.g., Fruhen et al., 2015; Re et al., 2013), with each individual posing under standardized conditions with neutral expression, closed 180 mouths, no adornments, direct gaze and hair pulled back from forehead. Each face in 181 our full face set was rated for attractiveness on a 1 (not at all attractive) to 7 (very attractive) scale. We used this data to manufacture an attractive male prototype and an attractive female prototype (the 10 most attractive men's/women's faces in the face set. Mean male attractiveness $=4.27, S D=0.30$, Mean female attractiveness $=4.63, S D=0.20$ ) and a less-attractive male prototype and a less-attractive female prototype (the 10 leastattractive men's/women's faces in the face set. Mean male attractiveness $=2.09, S D=0.38$,

Mean female attractiveness $=2.84, S D=0.48)$. The attractive and less-attractive faces that were used to manufacture each prototype differed significantly from one another on rated attractiveness (both $t>10.87$, both $p<.001$ ).

The resultant more-attractive and less-attractive versions of the 32 individual identities thus differed in attractive shape cues but were matched in skin colour, texture and identity (see Figure 1 for examples). Our 64 face images were standardized on pupil position, cropped to $400 \times 500$ pixels and then masked so that ears, body and background cues were removed and hair cues were minimized. Sixteen different identities (i.e. four attractive men, four less-attractive men, four attractive women, four less-attractive women) were used in the initial learning phase of a standard memory task. The un-manipulated versions of the eight male $(M=3.40, S D=.35)$ and eight female $(M=3.53, S D=.15)$ identities used here did not differ from one another in rated attractiveness $(t(14)=1.03 ; p=.32)$. 


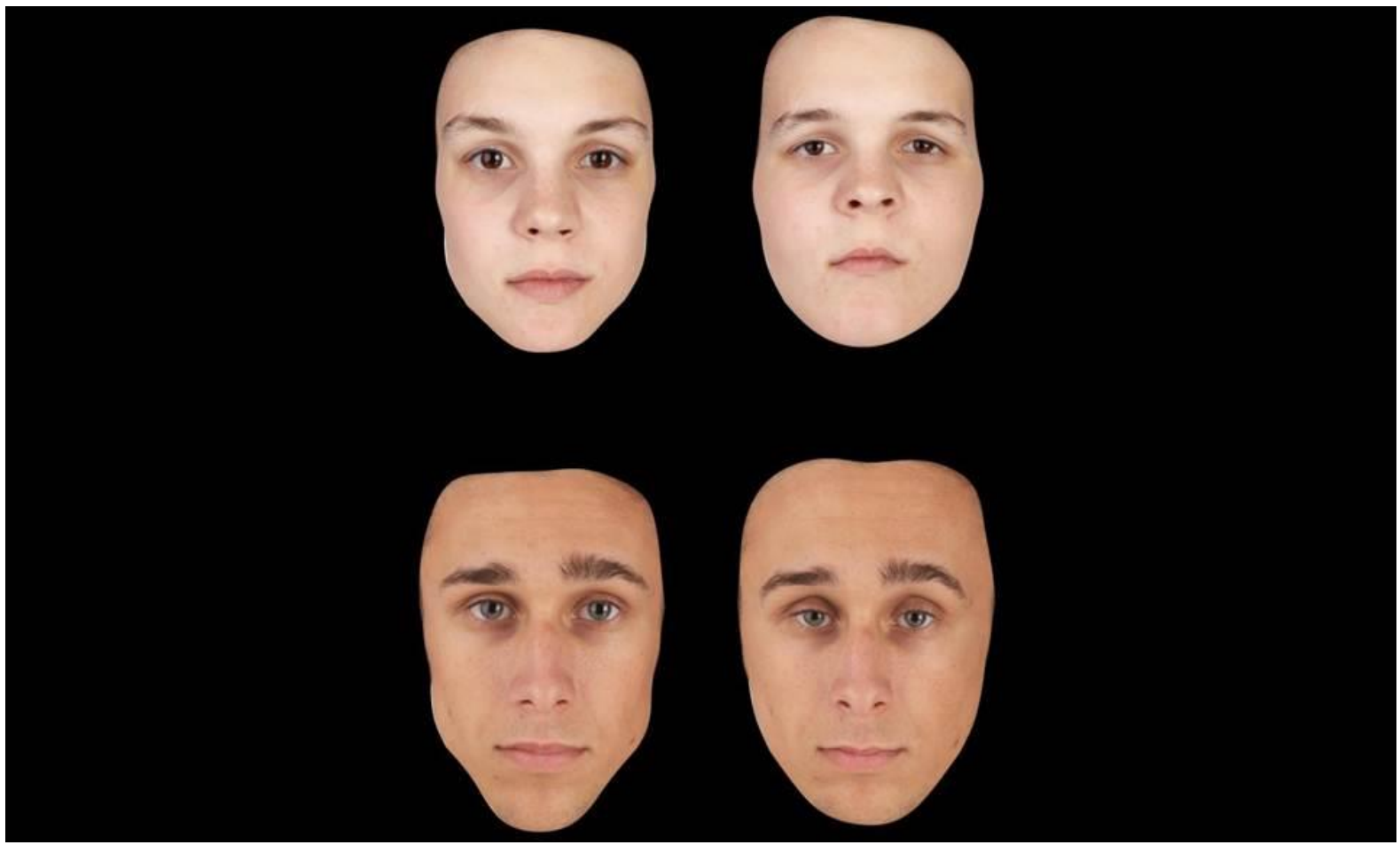

Figure 1. More-attractive (left) and less-attractive (right) versions of the same female (top) and male (bottom) identities. Identities were masked to remove external cues.

\subsection{Procedure}

The laboratory experiment consisted of three phases: A 'learning phase', where participants were asked to look closely at a set of faces in a slideshow; a 'priming phase', where we manipulated the perceived quality of participants' current romantic relationship (high-quality versus low-quality) and a 'test phase', where participants were asked to indicate if they recognized the faces from the first phase of the experiment. Prior to the central task on face memory, participants completed demographic measures including their self-rated attractiveness on a 1 (much less attractive than average) to 7 (much more attractive than average) scale.

At learning phase, participants viewed 16 different identities (i.e. four attractive men, four less-attractive men, four attractive women, four less-attractive women) centred on the screen and presented in a randomized order for 3 seconds each. In order to measure incidental encoding of faces, participants were not explicitly 
instructed to memorize the faces for a later task. Immediately following the learning phase, participants took part in a guided imagination prime (e.g., Chen et al., 1996; Little et al., 2007; Maner et al., 2009a; Watkins \& Jones, 2012). Here, participants were instructed: "Please take a few moments to imagine a point in your current romantic relationship where you felt particularly positive/negative about your relationship with your partner. Specifically, think about a time when you felt particularly close to/distant from him/her on an emotional level. Think for a few moments about your feelings at that time and visualize yourself in that situation". Thoughts about emotional closeness to partner were activated specifically in order to avoid possible confounds whereby participants focus on positive/negative points in their relationship that have little to do with actual closeness to their partner (e.g. receiving good or bad news while with their partner). Participants were then asked to rate the vividness with which they imagined the scenario on a 1 (not very vivid) to 7 (very vivid) scale. Research suggests that participants can accurately rate the vividness of their mental imagery (Pearson et al., 2011).

Immediately following the priming phase of the experiment, participants at test phase viewed (in a randomized order) 64 face stimuli, consisting of 32 studied identities and 32 foils. The studied identities consisted of the 16 test stimuli and the 16 alternate-versions of the test stimuli (i.e. four attractive versions of the four studied less-attractive men, four less-attractive versions of the four studied attractive men, four attractive versions of the four studied less-attractive women, four less-attractive versions of the four studied attractive women). The 32 foil stimuli consisted of moreattractive and less-attractive versions of eight unstudied men's faces and eight unstudied women's faces (i.e. 16 identities not seen at learning phase). Participants were simply asked to indicate if they recognized the face with a yes/no $(\mathrm{Y} / \mathrm{N})$ keypress. 
After the face memory task, participants completed a measure of perceived relationship quality (The Perceived Relationship Quality Component, PRQC; Fletcher et al., 2000), which measures relationship quality on six dimensions (satisfaction, commitment, intimacy, trust, passion, love) on a 1 (not at all) to 7 (extremely) scale. Scores on all subscales were correlated (all rho>.25 and <.72), except for the commitment and passion subscales $(r h o=.15, p=.20)$ and the trust and passion subscales (rho=.10, $p=.39$ ). A global measure of relationship quality was used in our analysis by averaging each participant's scores across all subscales (Mean global PRQC score $=6.14, \mathrm{SD}=.63$, range=3.61-7.00). Following the face memory experiment and questionnaires, participants were then thanked, debriefed, and reimbursed.

\subsection{Initial processing of data}

The true hit rate was calculated separately for four different categories of studied identity (face type: attractive, less-attractive; face sex: male, female), as the proportion of times across trials in which the original (i.e. seen) version of a face was recognized from the learning phase. False alarm rates were also calculated for the same four categories of identity, with separate values calculated for i) the false alarm rate for new faces (i.e. foils) and ii) the false alarm rate for altered versions of studied identities. These measures were used in subsequent analyses in addition to our main novel dependent measure (see summary statistics in Table 1). Here, we calculated sensitivity in memory separately for four different categories of studied-identity (face type: attractive, less-attractive; face sex: male, female). Data were coded as the proportion of times across trials that participants correctly-recognized an identity from the learning phase (i.e. hit rate) minus the proportion of times across trials that participants falsely-recognized an alternate version of a studied identity from the 
learning phase (i.e. falsely-recognized an attractive version of a studied, less-attractive male/female or falsely-recognized a less-attractive version of a studied, attractive male/female). Scores could, therefore, range between $+/-1$, with high scores on our dependent variable indicating greater sensitivity in memory for correct-versions of the studied identities. Critically, coding our dependent variable in this way ensures that any biases in memory for studied identities are attributable to the shape characteristics of the faces (i.e. attractive or less-attractive).

\section{Results}

\subsection{True hit rate (accuracy for correct versions of studied identities)}

First, we carried out one sample t-tests against the chance value of 0.5 to test whether hit rate for each category of studied identity was greater than would be expected by chance. Participants correctly-recognized attractive women ( $M=.79$, SEM=.03), lessattractive women $(M=.65, S E M=.03)$, attractive men $(M=.73, S E M=.03)$ and lessattractive men $(M=.63, S E M=.03)$ at levels greater than chance (all $t>3.90$, all $p<.001$, all $d>0.45$ and $<1.29$ ).

Next, we tested whether the rated vividness of mental imagery was equivalent across our two priming scenarios. Here, women imagined high-quality moments in their current relationship more vividly $(M=5.73, S E M=.23)$ than low-quality moments in their current relationship $(M=4.82, S E M=.30 ; t(72)=2.43 ; p=.018, r=0.28)$. In light of this, vividness was entered as an additional covariate in our main analysis. Here, a mixed-ANCOVA was conducted with true hit rate as the dependent variable, face sex (male, female) and face type (attractive, less-attractive) as the within-subjects' factors, priming condition (high-quality, low-quality) as the between-subjects factor and vividness of visual imagery, participant age, participant self-rated attractiveness and 
292 global perceived relationship quality as covariates. This analysis revealed no 293 significant effects or interactions (all $F<2.65$ all $p>$.10) except for a main effect of 294 priming condition $(F(1,68)=4.59 ; p=.036, \mathrm{np} 2=.06)$ and an interaction between face 295 sex and vividness of visual imagery $(F(1,68)=5.32 ; p=.024, \mathrm{np} 2=.07)$. The main effect 296 of priming condition reflected a tendency for greater hit rate when imagined 297 relationship quality was high $(M=.73, S E M=.03)$ than when imagined relationship 298 quality was low $(M=.66, S E M=.03, t(72)=1.86 ; p=.068, r=0.21)$. As there was no a priori 299 prediction for a relationship between vividness of visual imagery and face sex, this significant interaction was not explored further.

301

Table 1. Summary descriptive statistics ( $M$ and SEM) for women's face memory split by sex and attractiveness of the target across separate dependent measures.

\begin{tabular}{lcccc}
\hline & True hit rate & $\begin{array}{c}\text { False alarm } \\
\text { rate (foils) }\end{array}$ & $\begin{array}{c}\text { False alarm } \\
\text { rate (altered } \\
\text { versions) }\end{array}$ & $\begin{array}{c}\text { Discriminatory } \\
\text { sensitivity }\end{array}$ \\
\hline $\begin{array}{l}\text { Attractive } \\
\text { women }\end{array}$ & $.79(.03)$ & $.32(.02)$ & $.51(.03)$ & $.32(.04)$ \\
$\begin{array}{l}\text { Less-attractive } \\
\text { women }\end{array}$ & $.65(.03)$ & $.28(.03)$ & $.47(.03)$ & $.14(.05)$ \\
$\begin{array}{l}\text { Attractive men } \\
\text { Less-attractive } \\
\text { men }\end{array}$ & $.73(.03)$ & $.33(.03)$ & $.62(.03)$ & $.17(.03)$ \\
\hline
\end{tabular}




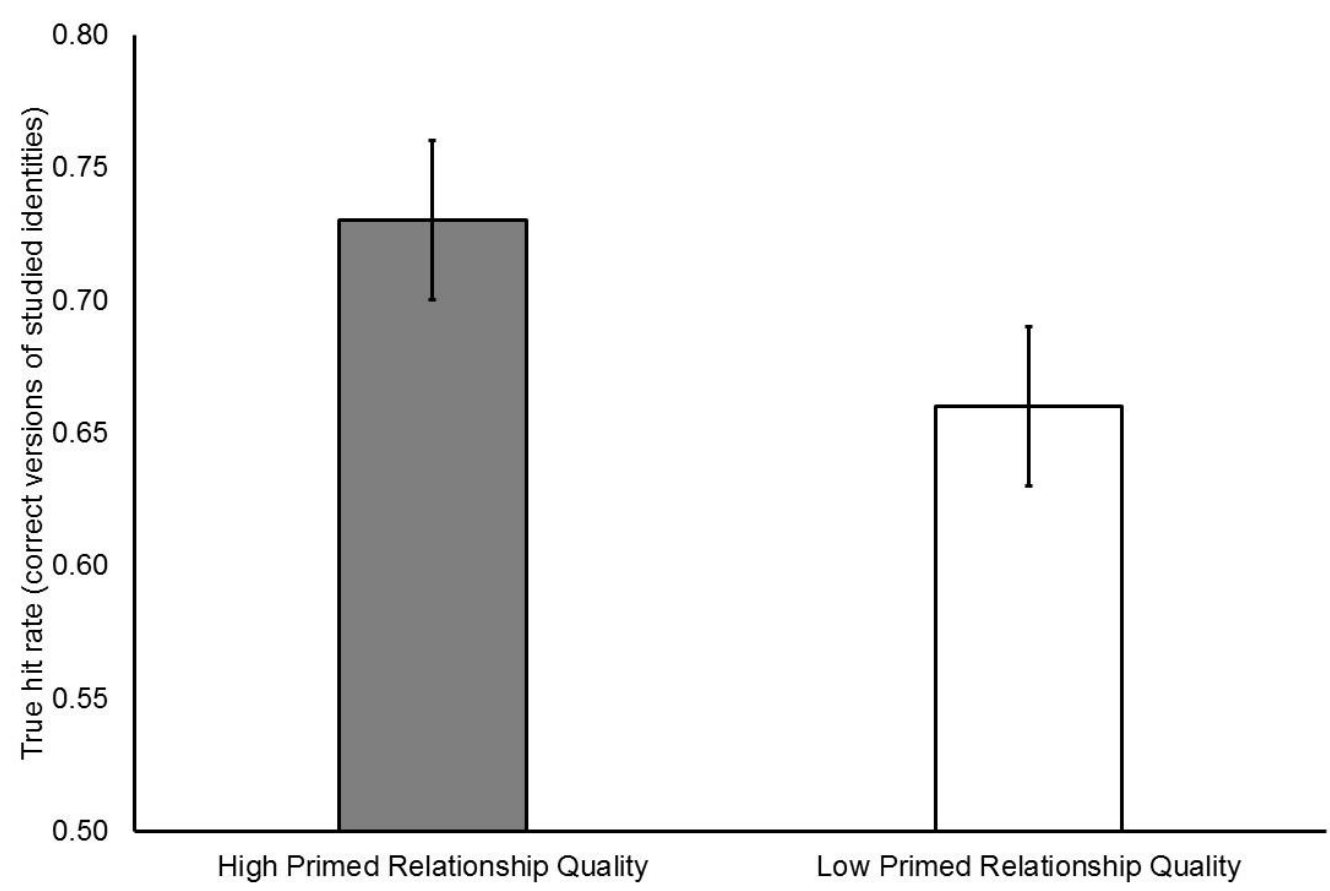

Figure 2. High romantic relationship quality strengthens hit rate in person memory compared to low romantic relationship quality (np2=.06).

\subsection{False alarm rate (new identities, i.e. foils)}

311 Initial one sample t tests against chance (i.e. 0.5) revealed that the false alarm rate for new identities was significantly less than chance for attractive male faces $(M=.33$, $S E M=.03, t(73)=6.31 ; p<.001, d=0.73)$, less-attractive male faces $(M=.27, S E M=.02$, $t(73)=9.83 ; p<.001, d=1.14)$, attractive female faces $(M=.32, S E M=.02, t(73)=7.27$; $p<.001, d=0.85)$ and less-attractive female faces $(M=.28, S E M=.03, t(73)=9.08$; $p<.001, d=1.06)$.

A mixed-ANCOVA was then conducted with false alarms for new identities as the dependent variable, face sex (male, female) and face type (attractive, lessattractive) as the within-subjects' factors, priming condition (high-quality, low-quality) as the between-subjects factor and vividness of visual imagery, participant age, participant self-rated attractiveness and global perceived relationship quality as covariates. This analysis revealed a significant interaction between face sex and priming condition $(F(1,68)=6.45 ; p=.013, \mathrm{np} 2=.09)$ and a significant interaction 
324 between face sex and face type $(F(1,68)=13.89 ; p<.001, \mathrm{np} 2=.17)$. A significant threeway interaction was found between face sex, face type and vividness of visual imagery $(F(1,68)=5.00 ; p=.029, \mathrm{np} 2=.07)$ and between face sex, face type and global perceived relationship quality $(F(1,68)=8.16 ; p=<.01, \mathrm{np} 2=.11)$. No other effects or interactions were significant (all $F<3.49$, all $p>06$ ).

The two-way interaction between face sex and priming condition reflected greater false alarms for new female faces when relationship quality was perceived to be low $(M=.34, S E M=.03)$ than when relationship quality was perceived to be high $(M=.27, S E M=.03, t(72)=2.06 ; p=.043, r=0.24)$ but no difference in false alarms for new male faces according to high $(M=.31, S E M=.03)$ versus low relationship quality $(M=.29, S E M=.03, t(72)=.57 ; p=.57)$. The significant interaction between face sex and face type reflected a stronger effect of facial attractiveness on false alarms for novel male faces $($ Mattractive=.33, SEM=.03, MLess-attractive=.27, SEM=.02, $t(73)=2.11 ; p=.038$, $r=.12)$ compared to novel female faces $\left(M_{\text {attractive }}=.32\right.$, SEM=.02, $M$ Less-attractive=.28, SEM=.03, $t(73)=1.53 ; p=.13$, see Figure 3 , panel b). The higher-order interaction between face sex, face type and vividness of visual imagery was not explored further as there was no specific a priori prediction for this interaction.

To interpret the three-way interaction between face sex, face type and global perceived relationship quality, separate correlations were conducted. These analyses revealed a positive correlation between global perceived relationship quality and false alarms for attractive new male faces which approached significance ( $r h o(74)=.22$; $p=.057$ ), but no corresponding relationship between perceived relationship quality and false alarms for less-attractive new male faces $(r h o(74)=-.02 ; p=.84)$, attractive new female faces $(r h o(74)=-.10 ; p=.38)$, or less-attractive new female faces $(r h o(74)=.01$; $p=.92)$. Of note, tests to compare the whether the slopes of two correlations differ 
significantly from one another (Lee \& Preacher, 2013) demonstrate that the correlation between self-rated attractiveness and false alarms for attractive new male faces differs significantly from the correlation between self-rated attractiveness and both i) false alarms for attractive new female faces $(Z=2.44, p=.015)$ and ii) false alarms for lessattractive new male faces $(Z=2.0, p=.046)$, but does not differ from the slope of the correlation between self-rated attractiveness and false alarms for less-attractive new female faces $(Z=1.43, p=.15)$.

\subsection{False alarm rate (altered versions of studied identities)}

A mixed-ANCOVA was conducted with false alarm rate for studied identities (i.e. recognizing the incorrect version of a studied identity) as the dependent variable, face sex (male, female) and face type (attractive, less-attractive) as the within-subjects' factors, priming condition (high-quality, low-quality) as the between-subjects factor and vividness of visual imagery, participant age, participant self-rated attractiveness and global perceived relationship quality as covariates. This analysis revealed a significant interaction between face sex and face type $(F(1,68)=14.93 ; p<.001$, $\mathrm{np} 2=.18$, see Figure 3, panel a) that was qualified by a higher-order interaction with self-rated attractiveness $(F(1,68)=8.50 ; p<.01, \mathrm{np} 2=.11$, see Figure 4$)$ and a separate three-way interaction between face sex, face type and global perceived relationship quality $(F(1,68)=8.23 ; p<.01, \mathrm{np} 2=.11)$. No other effects or interactions were significant (all $F<2.66$ all $p>$.10). The interaction between face sex and face type demonstrated that the positive effect of attractiveness on false alarms for incorrect versions of studied identities was stronger in male faces (Mattractive=.62, SEM=.03, MLessattractive $=.56, S E M=.03, t(73)=1.50 ; p=.14)$ than it was in female faces $\left(M_{\text {attractive }}=.51\right.$, $S E M=.03, M$ Less-attractive $=.47, S E M=.03, t(73)=1.03 ; p=.31)$. 
Separate correlational analyses were then conducted to interpret the three-way interactions between face type, face sex and our covariates (self-rated attractiveness and global perceived relationship quality). These analyses revealed a significant negative correlation between self-rated attractiveness and false alarms for lessattractive versions of studied male identities $(r h o(74)=-.27 ; p=.02)$. A significant negative correlation was also observed between self-rated attractiveness and false alarms for more-attractive versions of studied female identities $(r h o(74)=-.29 ; p=.013)$. No relationships were observed between self-rated attractiveness and false alarms for more-attractive versions of studied male identities $(r h o(74)=.08 ; p=.50)$ or lessattractive versions of studied female identities $(r h o(74)=-.03 ; p=.83)$. Separate regression analyses confirmed that self-rated attractiveness was negatively correlated with false alarms for less-attractive versions of studied male identities (Standardized beta $=-.23, t=-.20 ; p=.047)$, and explained $5.4 \%$ of the variance in the outcome variable (adjusted $r$ square $=.04$ ). Self-rated attractiveness was negatively correlated with false alarms for more-attractive versions of studied female identities (Standardized beta $=-$ $.35, t=-3.11 ; p<.01)$, and explained $12 \%$ of the variance in the outcome variable (adjusted $r$ square $=.11$ ).

A positive correlation was observed between global perceived relationship quality and false alarms for more-attractive versions of studied male identities $(r h o(74)=.31 ; p<.01)$. Global perceived relationship quality was not correlated with false alarms for less-attractive versions of studied male identities or false alarms for more- or less-attractive versions of studied female identities (all absolute rho<.11, all $p>$.37). Regression analyses confirmed that global perceived relationship quality predicted false alarms for more-attractive versions of studied male identities 
398 (Standardized beta $=.29, t=2.61 ; p=.011$ ) and explained $9 \%$ of the variance in the outcome variable (adjusted $\mathrm{r}$ square $=.07$ ).

400

\subsection{Discriminatory sensitivity: Different shape versions of studied identities}

402 One sample t-tests against chance (i.e. 0) were conducted in order to test whether women, on average, were sensitive to the correct-versions of studied identities in memory (i.e. recognizing the correct version of the face and not falsely-recognizing the alternate version of the same studied identity). Sensitivity in memory was significantly greater than chance for correct-versions of studied identities $(M=.16$, $S E M=.02 ; t(73)=7.86 ; p<.001, d=0.91)$. Moreover, women's memories were sensitive to studied versions of attractive men's $(M=.17, S E M=.03 ; t(73)=5.23 ; p<.001, d=0.61)$ and women's faces $(M=.32, S E M=.04 ; t(73)=8.45 ; p<.001, d=0.98)$ and less-attractive women's faces $(M=.14, S E M=.05 ; t(73)=3.10 ; p<.01, d=0.36)$. General sensitivity to studied less-attractive men's faces was not significant $(M=.01, S E M=.04 ; t(73)=.33$; $412 p=.74)$.

A mixed-ANCOVA was conducted with sensitivity in memory for correct versions of studied identities as the dependent variable, face sex (male, female) and face type (attractive, less-attractive) as the within-subjects factors, priming condition (highquality, low-quality) as the between-subjects factor and vividness of visual imagery, participant age, participant self-rated attractiveness and global perceived relationship quality as covariates. This analysis revealed a significant interaction between face sex and face type $(F(1,68)=5.74 ; p=.02$, np2 $=.08$, see Figure 3 , panel $c)$. This interaction reflected a greater effect of facial attractiveness on sensitivity in person memory when responding to women $(t(73)=3.29 ; p<.01, r=0.19)$ than when responding to men 
a) amore-attractive aless-attractive

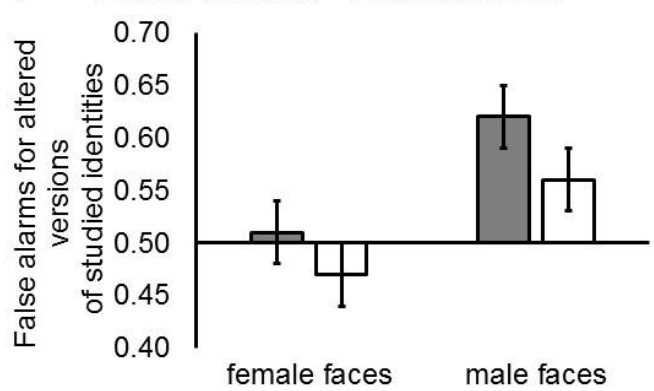

b) amore-attractive aless-attractive

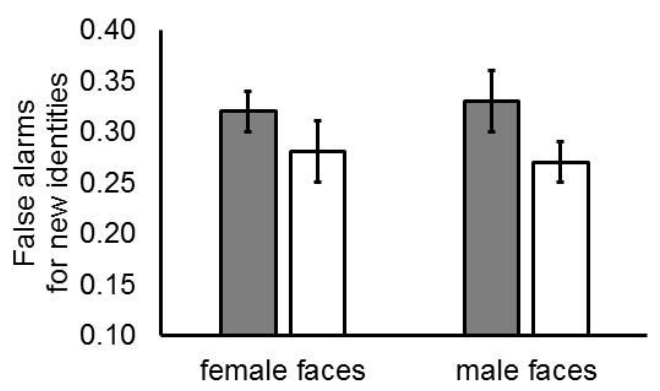

c)

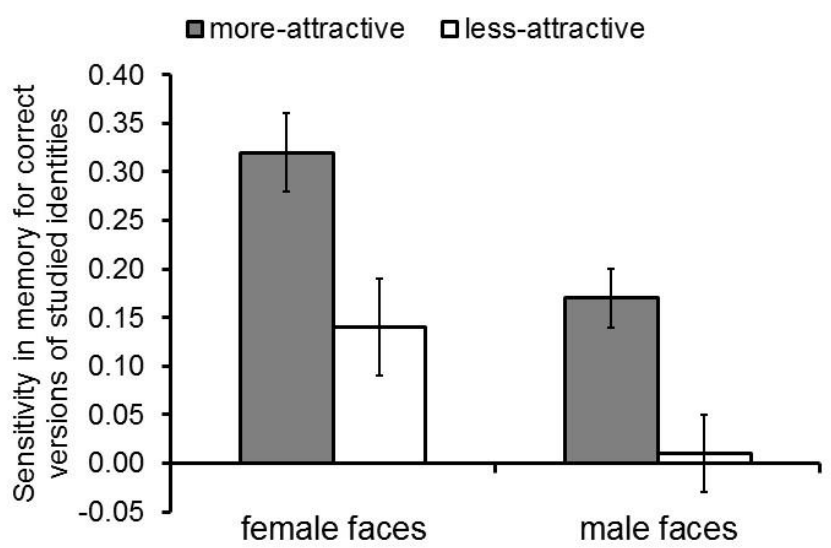

Figure 3. Significant interactions between the sex of face recognized and the attractiveness of face recognized. Panel a: Women were biased toward false alarms for altered versions of studied identities if the face was altered to be more attractive, and this effect was stronger for men's faces than women's faces (np2=.18). Panel b: False alarms for novel identities were greater for attractive faces, and this effect was stronger for men's faces than women's faces (np2=.17). Panel c: Facial attractiveness had a greater effect on sensitivity in person memory (ability to distinguish between a seen and unseen/altered version of a studied identity) when women remembered other women than when they remembered other men (np2=.08).

Importantly, our significant interaction between sex of face recognized and attractiveness of face recognized was qualified by a higher-order interaction with selfrated attractiveness $(F(1,68)=4.64 ; p=.035, \mathrm{np} 2=.06$, see Figure 4 , panel $\mathrm{c})$. No other effects or interactions were significant (all $F<3.57$, all $p>.063$ ). In order to interpret our higher-order interaction, we tested for correlations between self-rated attractiveness and our dependent variable (i.e. sensitivity in memory for each category of studied identity: attractive women, attractive men, less-attractive women, less-attractive men).

441 These analyses revealed that women's self-rated attractiveness was positively correlated with sensitivity in memory for attractive versions of studied men's faces 
$443(\operatorname{rho}(74)=.27, p=.02)$, but was not correlated with sensitivity in memory for less-

444 attractive versions of studied men's faces or attractive/less-attractive versions of

445 studied women's faces (all rho<.22, all p>.062). Separate linear regression analyses

446 confirmed that the relationship between self-rated attractiveness and sensitivity

447 among women in their memory for attractive men approached significance

448 (Standardized beta $=.23, t=1.96, p=.054$ ) and explained $5 \%$ of the variance in the 449 outcome variable (adjusted $r$ square $=.04$ ).

a)

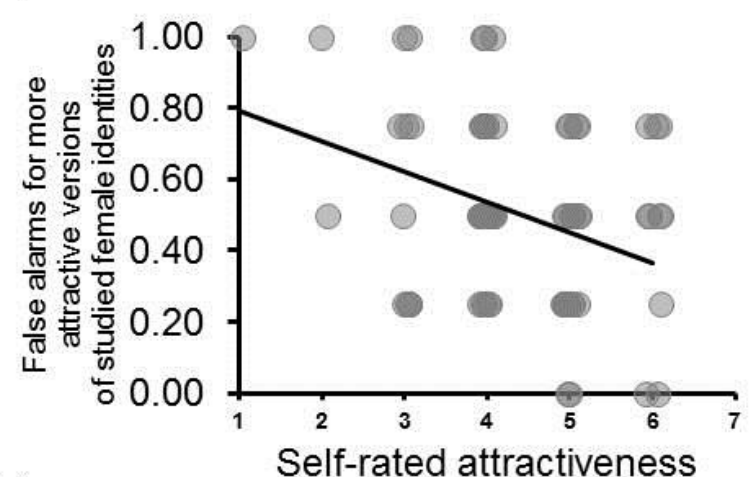

b)

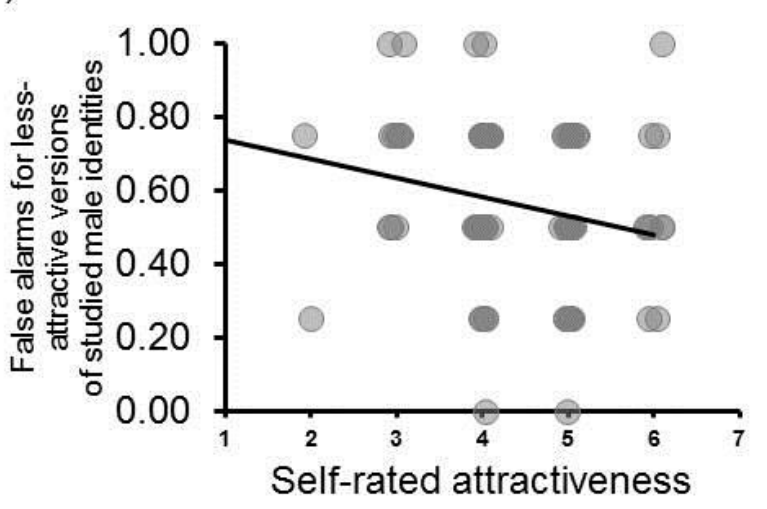

c)

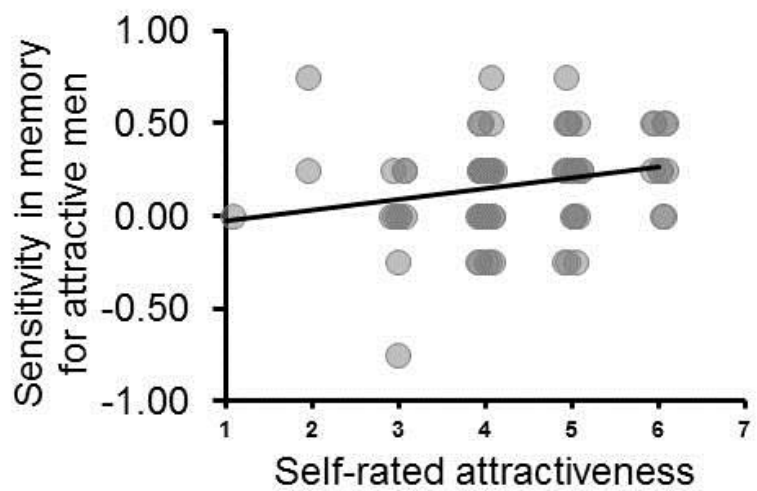

450

Figure 4. Relationships between self-rated attractiveness and women's face memory $(\mathrm{N}=74)$. Less-attractive women have a stronger bias toward remembering women as more attractive than their original image (panel a, $r h o=-.29$ ), and remembering men as less attractive than their original image (panel b, rho=-.27). Attractive women's memories are more sensitive to cues to high attractiveness in men's faces (panel c,

\section{Discussion}


459 Our findings demonstrate that while women in a long-term romantic relationship are 460 generally accurate in remembering studied-faces, their memory for others is shaped by the sex and attractiveness of the target. Specifically, our data show that facial attractiveness strengthens incidental encoding, and subsequent sensitivity in memory for rivals for mates (i.e. other women), when examining their ability to distinguish between a seen and unseen version of a studied identity that differs in shape cues to attractiveness. By contrast, when examining biases in memory (i.e. false alarms) for both new identities and versions of studied identities that had been altered to look more or less-attractive than the original (i.e. seen) face image, the effect of facial attractiveness on false alarms was stronger for alternate/extra-pair mates (i.e. other men) than it was for rivals for mates (other women). Collectively, these findings suggest that, even with minimal exposure to faces, women are better at retaining knowledge about the identity and appearance of attractive women, but have a stronger positive bias in their memory for men's appearance and stronger false memory for attractive men more generally.

Critically, our observed interactions between the sex and attractiveness of remembered faces were qualified by factors that were predicted to shape women's ability and/or willingness to compete for an extra-pair partner. Here, women's own attractiveness was positively correlated with sensitivity in memory for attractive shape cues in studied-men's faces. In addition, when examining biases in memory for facial appearance, less-attractive women had a stronger bias than their attractive peers to remember women as more attractive than their original studied image and to remember men as less attractive than their original studied image. Collectively, these findings suggest that women's 'market value' shapes both sensitivity and biases for other people on the attractiveness dimension in ways that may function for successful 
mating competition. Our data on sensitivity in memory suggests that the memories of women in long-term relationships may be specialized to retain information about attractive rivals for mates (i.e. to maintain the relationship), while factors that alter the potential costs of competing for an alternate mate (own attractiveness) predict their memory for men on the attractiveness dimension. By contrast, our data on false alarm rates suggests that while women may generally be biased toward positive illusions of men's attractiveness, this bias is attenuated among women of relatively low mate value who, in turn, have stronger positive illusions of other women's attractiveness. Our findings reveal a very subtle pattern of results for both bias and accuracy in women's memories for other people in light of their mate value, which may have implications for relationship maintenance.

Our central prediction, that activating positive or negative memories about women's current romantic relationship would have a direct-effect on memory for attractive faces, was not supported. Our data instead suggest that person memory (hit rate) is generally strengthened by activating positive memories about a current relationship, independent of the sex or attractiveness of the target. Moreover, when examining false memories for new faces, women are more likely to commit these errors for other women's faces when primed relationship quality is low compared to when it is high. In addition, when relationship quality was examined using a psychometric measure, women in relatively good romantic relationships were more likely to make false memory errors for attractive alternate/extra-pair mates than they were for attractive rivals for their mate and had stronger positive biases toward attractive men (remembering them as more attractive than their original image) than their peers in relatively low-quality romantic relationships. Although these latter findings for psychometric relationship quality contradict our initial prediction (that low 
relationship quality would be related to stronger memory for attractive faces) they are still consistent with accounts in the literature on human and nonhuman mate choice whereby access to a source of investment (a romantic partner) can heighten preferences for or orientation toward cues to biological quality in a potential extra-pair partner (Shackelford \& Goetz, 2007; see also Jennions \& Petrie, 2000). Moreover, they are consistent with the general theoretical proposal that romantic motivations shape memory for the opposite-sex (Karremans et al., 2011) and recent evidence which suggests that indices of relationship quality, such as passion, are correlated with the remembered facial attractiveness and facial trustworthiness of women's partners using reverse-correlation paradigms (Gunaydin \& DeLong, 2015). This latter evidence is consistent with our findings since it suggests that positive relationship quality may strengthen encoding/retention of physical cues to male quality more generally. Further work that explicitly tests women's memory of their partner versus other men using these techniques could resolve whether there are differences in how women differentiate their partner versus other men on the attractiveness dimension according to relationship quality.

Our data suggest that our priming techniques were not sufficient to alter accuracy or sensitivity in memory for faces on the attractiveness dimension. Although it would be speculative to suggest why person memory (hit rate) in general is enhanced by positive romantic relationship quality, further work could test for contexts in which valence alters person memory, perhaps using different priming techniques. Indeed, recent work using priming techniques that are arguably more powerful (e.g. writing versus imagining) suggests that these measures have direct effects on important romantic behaviours, such as reducing the decline in perceived relationship quality over time through reappraisal of prior conflict (Finkel et al., 2013). In addition, although 
534 our prime tests for effects of positive versus negative romantic relationship quality on person memory (i.e. by activating thoughts about closeness versus distance to romantic partner), further work could test the effects of this prime against an imagination prime that enhances positive versus negative mood more generally or aspects of positive versus negative relationship quality that are unrelated to emotional closeness, in order to examine whether our findings generalize to other contexts related to positive valence.

Our findings are consistent with our prediction that the high 'market demand' of attractive women (Noë \& Hammerstein, 1994; see also Wincenciak et al., 2015), which in turn would reduce the costs of mating competition (Vaillancourt, 2013), shapes sensitivity in their memory for attractive shape cues in men's faces. If learning incurs fitness costs (reviewed in Dukas, 2008), cognitive resources for tasks such as mating competition should be allocated judiciously. That women's memory for attractive male shape cues was predicted by their own attractiveness is consistent with recent evidence which suggests that high-quality women may be better placed to translate their mate preferences into actual choices (Wincenciak et al., 2015) and suggests that memory for potential extra-pair (or alternate) partners is allocated judiciously among women according to their own attractiveness. Indeed, our findings are also consistent with prior work demonstrating that measures of women's own attractiveness are correlated with their reported number of extra-pair partners and long-term number of sexual partners (Hughes et al., 2003; Rhodes et al., 2005), suggesting a potential cognitive mechanism for these behaviours in women.

In sum, our findings demonstrate that incidental encoding and retention of information about briefly-presented faces is shaped according to women's own traits and circumstances. The women in our sample were, in general, more accurate in 
remembering others when thinking about positive moments in their relationship, and more sensitive to women's identity and appearance than they were to men's identity and appearance. While women had positive biases in recounting men's attractiveness, women who considered themselves of lower mate value had negative biases for men's attractiveness and were more likely to remember women as more attractive than their original encounter. Our data suggest that while partnered women's memory may be sensitive toward relationship maintenance and competition with attractive same-sex rivals, factors that reduce the potential costs of mating competition for extra-pair partnerships (i.e. market demand) shape sensitivity in their memory for cues to male quality and subtle perceptual biases in their recollection of others on the attractiveness dimension. Our findings speak to the sophisticated nature of the social brain (Dunbar, 2012; see also Byrne and Whiten, 1998), shaped by natural selection and/or personal experience to maximize fitness (Kenrick et al., 2010), and demonstrate great flexibility in romantic cognition and, potentially, episodic foresight (Suddendorf et al., 2009), as women navigate a long-term romantic relationship.

\section{Acknowledgements}

This research was gratefully-funded by a Carnegie Research Incentives Grant awarded to the first-author (Ref \#70014).

\section{References}

Ackerman, J. M., Griskevicius, V. \& Li, N. P. (2011). Let's get serious: Communicating commitment in romantic relationships. Journal of Personality and Social Psychology, 100, 1079-1094.

Bailey, N. \& Zuk, M. (2009). Field crickets change mating preferences using remembered social information. Biology Letters, 5, 449-451.

Becker, D. V., Kenrick, D. T., Guerin, S., \& Maner, J. K. (2005). Concentrating on beauty: Sexual selection and sociospatial memory. Personality and Social Psychology Bulletin, 31, 1643-1652. 
Berscheid, E. (2010). Love in the fourth dimension. Annual Review of Psychology, 61, $1-25$.

Betzig, L. (1989). Causes of conjugal dissolution: A cross-cultural study. Current Anthropology, 30, 654-676.

Brennan, P. A. \& Kendrick, K. M. (2006). Mammalian social odours: Attraction and individual recognition. Philosophical Transactions of the Royal Society of London B, 361, 2061-2078.

Byrne, R. \& Whiten, A. (1988). Machiavellian Intelligence. Oxford University Press.

Chen, S., Shechter D. \& Chaiken S. (1996). Getting at the truth or getting along: accuracy- versus impression-motivated heuristic and systematic processing. Journal of Personality and Social Psychology, 71, 262-275.

Conway, M. A. (2005). Memory and the self. Journal of Memory and Language, 53, 594-628.

De Graaf, P. M. \& Kalmijn, M. (2006). Divorce motives in a period of rising divorce: Edivence from a Dutch life-history survey. Journal of Family Issues, 27, 483505.

Dion, K., Berscheid, E. \& Walster, E. (1972). What is beautiful is good. Journal of Personality and Social Psychology, 24, 285-290.

Dunbar, R. I. M. (2012). The social brain meets neuroimaging. Trends in Cognitive Sciences, 16, 101-102.

Dukas, R. (2008). Evolutionary biology of insect learning. Annual Review of Entomology, 53, 145-160.

Finkel, E. J., Slotter, E. B., Luchies, L. B., Walton, G. M. \& Gross, J. J. (2013). A brief intervention to promote conflict-reappraisal preserves marital quality over time. Psychological Science, 24, 1595-1601.

Fletcher, G. O., Simpson, J. A. \& Thomas, G. (2000). The measurement of perceived relationship quality components: A confirmatory factor analytic approach. Personality and Social Psychology Bulletin, 26, 340-354.

Fruhen, L. S., Watkins, C. D. \& Jones, B. C. (2015). Perceptions of facial attractiveness, dominance and trustworthiness predict managerial pay awards in experimental tasks. Leadership Quarterly, 26, 1005-1016.

Gangestad, S. W. \& Scheyd, G. J. (2005). The evolution of human physical attractiveness. Annual Review of Anthropology, 34, 523-548.

Gangestad, S. W., Merriman, L. A. \& Thompson, M. E. (2010). Men's oxidative stress, fluctuating asymmetry and physical attractiveness. Animal Behaviour, 80, 1005-1013.

Gunaydin, G. \& DeLong, J. E. (2015). Reverse correlating love: Highly passionate women idealize their partner's facial appearance. PLoS One, 10, e0121094.

Hahn, A. C. \& Perrett, D. I. (2014). Neural and behavioral responses to attractiveness in adult and infant faces. Neuroscience and Biobehavioral Reviews, 46, 591603.

Hughes, S. M., Dispenza, F. \& Gallup, G. G. (2004). Ratings of voice attractiveness predict sexual behaviour and body configuration. Evolution and Human Behavior, 25, 295-304.

Jennions, M. D. \& Petrie, M. (2000). Why do females mate multiply? A review of the genetic benefits. Biological Reviews, 75, 21-64.

Karney, B. \& Bradbury, T. (2005). Contextual influences on marriage. Current Directions in Psychology, 14, 171-228. 
Karremans J. C., Dotsch R. \& Corneille, O. (2011). Romantic relationship status biases memory of faces of attractive opposite-sex others: Evidence from a reversecorrelation paradigm. Cognition, 121, 422-426.

Kenrick, D. T., Neuberg, S. L., Griskevicius, V.., Becker, D. V. \& Schaller, M. (2010). Goal-driven cognition and functional behavior: The fundamental-motives framework. Current Directions in Psychological Science, 19, 63-67.

Krupp, D. B., DeBruine, L. M. \& Jones, B. C. (2011). Apparent health encourages reciprocity. Evolution and Human Behavior, 32, 198-203.

Langlois, J. H., Kalakanis, L., Rubenstein, A. J., Larson, A., Hallam, M. \& Smoot, M. (2000). Maxims or myths of beauty? A meta-analytic and theoretical review. Psychological Bulletin, 126, $390-423$.

Lee, I. A. \& Preacher, K. J. (2013). Calculation for the test of the difference between two dependent correlations with one variable in common. Available from http://quantpsy.org/corrtest/corrtest2.htm

Lie, H. C., Rhodes, G. \& Simmons, L. W. (2008). Genetic diversity revealed in human faces. Evolution, 62, 2473-2486.

Little, A. C., Jones, B. C. \& DeBruine, L. M. (2011). Facial attractiveness: Evolutionary based research. Philosophical Transactions of the Royal Society B, 366, 16381659.

Little, A. C., Cohen, D. L., Jones, B. C. \& Belsky, J. (2007). Human preferences for facial masculinity change with relationship type and environmental harshness. Behavioral Ecology and Sociobiology, 61, 967-973.

Maner, J. K., Miller, S. L., Rouby, D. A. \& Gailliot, M. T. (2009a). Intrasexual vigilance: the implicit cognition of romantic rivalry. Journal of Personality and Social Psychology, 97, 74-87.

Maner, J., Gailliot, M. T. \& Miller, S. L. (2009b). The implicit cognition of relationship maintenance: Inattention to attractive alternatives. Journal of Experimental Social Psychology, 45, 174-179.

Maner, J., Rouby, D. A. \& Gonzaga, G. (2008). Automatic inattention to attractive alternatives: The evolved psychology of relationship maintenance. Evolution and Human Behavior, 29, 343-349.

Maner, J., Gailliot, M. T. \& DeWall, C. N. (2007a). Adaptive Attentional Attunement: Evidence for Mating-Related Perceptual Bias. Evolution and Human Behavior, 28, 28-36.

Maner, J. K., Gailliot, M. T., Rouby, D. A. \& Miller, S. L. (2007b). Can't take my eyes off you: Attentional adhesion to mates and rivals. Journal of Personality and Social Psychology, 93, 389-401.

Marzi, T. \& Viggiano, M. P. (2010). When memory meets beauty: Insights from eventrelated potentials. Biological Psychology, 84, 192-205.

Noë, R. \& Hammerstein, P. (1994). Biological markets: Supply and demand determine the effect of partner choice in cooperation, mutualism and mating. Behavioral Ecology and Sociobiology, 35, 1-11.

Oosterhof, N. N. \& Todorov, A. (2008). The functional basis of face evaluation. Proceedings of the National Academy of Sciences, 105, 11087-11092.

Opie, C., Atkinson, Q. D., Dunbar, R. I. M. \& Shultz, S. (2013). Male infanticide leads to social monogamy in primates. Proceedings of the National Academy of Sciences USA, 110, 13328-13332.

Pearson, J., Rademaker, R. \& Tong, F. (2011). Evaluating the mind's eye: the metacognition of visual imagery. Psychological Science, 22, 1535-1542. 
Perilloux, C. \& Buss, D. M. (2008). Breaking up romantic relationships: Costs experienced and coping strategies deployed. Evolutionary Psychology, 6, 164181.

Prokop, P. \& Fedor, P. (2011). Physical attractiveness influences reproductive success of modern men. Journal of Ethology, 29, 453-458.

Puts, D. A., Barndt, J. L., Welling, L. L. M., Dawood, K. \& Burriss, R. P. (2011). Intrasexual competition among women: Vocal femininity affects perceptions of attractiveness and flirtatiousness. Personality and Individual Differences, 50, 111-115.

Rantala, M., Moore, F. R., Skrinda, I., Krama, T., Kivleniece, I., Kecko, S. \& Krams, I. (2012). Evidence for the stress linked immunocompetence handicap in humans. Nature Communications, 3, 694, doi:10.1038/ncomms1696.

Re, D. E., DeBruine, L. M., Jones, B. C. \& Perrett, D. I. (2013). Facial cues to perceived height influence leadership choices in simulated war and peace contexts. Evolutionary Psychology, 11, 89-103.

Rhodes, G. (2006). The evolutionary psychology of facial beauty. Annual Review of Psychology, 57, 199-226.

Rhodes, G., Simmons, L. W. \& Peters, M. (2005). Attractiveness and sexual behaviour: Does attractiveness enhance mating success? Evolution and Human Behavior, 26, 186-201.

Sell, A., Tooby, J. \& Cosmides, T. (2009). Formidability and the logic of human anger. Proceedings of the National Academy of Sciences, 106, 15073-15078.

Shackelford, T. K. \& Goetz, A. T. (2007). Adaptation to sperm competition in humans. Current Directions in Psychological Science, 16, 47-50.

Suddendorf, T., Addis, D. R. \& Corballis, M. C. (2009). Mental time travel and the shaping of the human mind. Philosophical Transactions of the Royal Society of London B, 364, 1317-1324.

Tiddeman B, Burt M, Perrett D. (2001). Prototyping and transforming facial textures for perception research. IEEE Computer Graphics and Applications, 21, 42-50.

Todorov, A., Olivola, C. Y., Dotsch, R. \& Mende-Siedlecki, P. (2015). Social attributions from faces: Determinants, consequences, accuracy, and functional significance. Annual Review of Psychology, 66, 1-27.

Tsukiura, T. \& Cabeza, R. (2011). Remembering beauty: Roles of orbitofrontal and hippocampal regions in successful memory encoding of attractive faces. Neurolmage, 54, 653-660.

Vaillancourt, T. (2013). Do human females use indirect aggression as an intrasexual competition strategy? Philosophical Transactions of the Royal Society of London B, $368 \mathrm{http}: / / \mathrm{dx}$.doi.org/10.1098/rstb.2013.0080.

Watkins, C. D. \& Jones, B. C. (2012). Priming men with different contest outcomes modulates their dominance perceptions. Behavioral Ecology, 23, 539-543.

Wiese, H., Altmann, C. S. \& Schweinberger, S. R. (2014). Effects of attractiveness on face memory separated from distinctiveness: Evidence from event-related brain potentials. Neuropsychologia, 56, 26-36.

Willis, J. \& Todorov, A. (2006). First impressions: making up your mind after a 100-ms exposure to a face. Psychological Science, 17, 592-598.

Wincenciak, J., Fincher, C. L., Fisher, C., Hahn, A. C., Jones, B. C. \& DeBruine, L. M. (2015). Mate choice, mate preference, and biological markets: The relationship between partner choice and health preference is modulated by women's own attractiveness. Evolution and Human Behavior, 36, 274-278. 
734 Wlodarski, R. \& Dunbar, R. I. M. (2013). Examining the possible functions of kissing in romantic relationships. Human Nature, 42, 1415-1423.

737 